\title{
Preparation and Characterization of New Nanoparticles Compounds based on Iron and Iodine as Prospective Materials for Medical Applications
}

\author{
M. I. Aydia 1,*, R. O. Abdel Rahman', A. M. Rashad ${ }^{3}$, K.M. El-Azony ${ }^{1}$ \\ ${ }^{(1)}$ Radioactive Isotopes and Generators Department, Hot Labs. Center, Egyptian Atomic Energy Authority, Cairo, Egypt. \\ ${ }^{(2)}$ Radioactive Waste Management Department, Hot Labs. Center, Egyptian Atomic Energy Authority, Cairo, Egypt. \\ ${ }^{(3)}$ Central Lab. For Elemental \& Isotopic Analysis, Accelerators and Ion Sources Department, NRC, Egyptian Atomic Energy \\ Authority, Cairo, Egypt.
}

\begin{tabular}{l} 
ART ICLE INFO \\
\hline Article history: \\
Received: $23^{\text {rd }}$ Aug. 2020 \\
Accepted: $11^{\text {th }}$ Apr. 2021 \\
\hline Keywords: \\
Magnetic nanoparticles; \\
hyperthermia; \\
Specific absorption rate \\
(SAR); \\
Magnetization; \\
Cytotoxicity.
\end{tabular}

\section{ABSTRACT}

Developed compounds of magnetic iron iodide nanoparticles (MIINPs) were simply and cheaply prepared for their potential use in the bioapplications through magnetic hyperthermia therapy, using a co-precipitation method based on the study of various factors such as temperature, molar ratio and pH. Two samples of MIINPs were chosen based on the proportions of iorn and iodide in the sample, respectively 52 and $48 \%$ in MIINPs-1 and 45 and 55\% in MIINPs-2. Fourier transforms infrared spectroscopy (FTIR), thermal analysis (TA), energy dispersive X-ray spectroscopy (EDX), and X-ray diffraction (XRD) were used to characterize the prepared compounds. The chemical composition of MIINPs-1 and MIINPs-2 was determined by means of an elemental analysis using EDX technique and confirmed using structural modeling by Visual Minteq 3.0, Match 1.9 and Endeavour 1.7 software. The magnetic properties of both samples were measured and found to be superparamagnetic materials. Both MIINPs-1 and MIINPs-2 samples have approximately the same magnetization (nearly $36.1 \mathrm{emu} / \mathrm{g}$ ) in the 500 Oe coercive field as safe operating limits for MHT achieving $94 \%$ and $86.4 \%$ of their saturation values respectively. Specific absorption rates (SARs) were practically and theoretically determined as well as it was found that the practical SAR value of MIINPs-1 is much closer to the theoretical value than in the case of MIINPs-2.

\section{INTRODUCTION}

Magnetite nanoparticles (MNPs) are currently used in many life sciences areas, including magnetic hyperthermia treatment (MHT), chemo-hyperthermia treatment of bone and lung cancers [1, 2], magnetic resonance imaging (MGI) [3, 4], drug delivery [5], antibacterial agents for water treatment [6]. $\mathrm{Fe}_{3} \mathrm{O}_{4}$ superparamagnetic iron oxide nanoparticles (SPION) are approved for clinical use by the US Food and Drug Administration [7], it is a biocompatible compound with very low toxicity, making it one of the best and most preferred stable materials for future medical applications.

The preparation methods have a strong influence on the magnetic properties of MNPs because of the dramatic dependence of the magnetic properties on the morphology and structure of the MNPs. Developing the synthesis methods to allow better control of particle size, size distribution, shape and crystal defects have long been a scientific and technological challenge. The two major chemical problems emerged during the preparation of MNPs, one being the synthesis of monodisperse nano-structures, and the other being reproducibility [8]. The preparation methods of metals or metal oxide nanoparticles are relatively complex and expensive compared to the preparation of iron oxide nanoparticles, due to their low cost preparation [8], and low toxicity [9]. Different techniques for preparing magnetic iron-oxide nanoparticles have been used, such as co-precipitation [10-15]. and hydrothermal method [16-20]. Although, the co-precipitation techniques formed relatively low crystallinity and poormagnetic properties of the prepared materials [21-23]. However, it was used due to its simplicity and relatively small environmental impact $[11,24-35]$. 
Magnetic iron iodide Nanoparticles (MIINPs) are novel compounds, which have not been recognized in the literature and prepared on the basis of the iodide addition, during the preparation of magnetic iron oxides at high $\mathrm{pH}$ and certain conditions using co-precipitation technique. On the other hand, the hydrothermal methods are not appropriate for preparing compounds containing iodine due to loss of iodine during the preparation process $[36,37]$. Magnetite NPs have been stabilized by a variety of ligands such as dextran [38], cationic liposomes [39], polyvinyl alcohol, hydrogel [40], lauric acid [41- 42], citric acid [43] and maghemite NPs stabilized by dextran [38].

The hysteresis curves of the Hydroxyapatite-coated magnetite nanoparticles (HA-MNPs) and MNPs have been measured with an applied coercive field at 8500 Oe. It showed the saturation magnetization (Ms) of HA-MNPs about $10 \mathrm{emu} \mathrm{g}^{-1}$, which is $\sim 25 \%$ of MNPs $\left(\sim 40 \mathrm{emu} \mathrm{g}^{-1}\right)$ [44]. These results indicated that coating of MNPs with the HA nanocrystallites was significantly affected the magnetization properties. The use of MNPs in MHT is based on their magnetic properties and the safe external alternating magnetic field (AMF) [45-49] to assess the specific absorption rate (SAR) value (watt/g), is a measure of the energy rate when MNPs is exposed to an electromagnetic field, then determine the generated heat $\left(41-46^{\circ} \mathrm{C}\right)[45-49]$.

This work focused on the preparation of new MIINPs using a simple and cheap co-precipitation method to study the effect of iodine on their chemical compositions and magnetic properties for MHT applications. In order to recognize the crystallographic, morphological, and chemical composition of the chosen MIINPs samples, they were practically characterized by various techniques such as FTIR, XRD, XRF, EDX, and TEM and confirmed computationally by structural modeling using Visual Minteq 3.0, Match 1.9, and Endeavour 1.7 software. Then, the magnetic properties were measured to study the effect of iodine ratio on magnetization behavior and on the obtained specific absorption rate (SAR) values of the both MIINPs samples. Due to the possibility to use these compounds in the medical field, measurements of cytotoxicity were performed to ensure their safety for medical uses.

\section{Materials and Methods}

\section{Materials}

Analytical grade ferrous sulfate heptahydrate $\left(\mathrm{FeSO}_{4} .7 \mathrm{H}_{2} \mathrm{O}\right)$, ferric ammonium sulfate dodecahydrate $\left(\mathrm{NH}_{4} \mathrm{Fe}\left(\mathrm{SO}_{4}\right)_{2}{ }_{12} \mathrm{H}_{2} \mathrm{O}\right)$, and potassium iodide (KI) were purchased from Fisher Scientific Company (USA) and
Honeywell Company (Germany) and used for MIIN preparation

\section{Optimal conditions of MIINPs preparation}

The $\mathrm{FeSO}_{4} .7 \mathrm{H}_{2} \mathrm{O}$ and $\mathrm{NH}_{4} \mathrm{Fe}\left(\mathrm{SO}_{4}\right)_{2} \quad 12 \mathrm{H}_{2} \mathrm{O}$ equimolar solutions at $0.18 \mathrm{M}$ were mixed in water and heated to the appropriate temperature, then added a specified quantity of KI solution with stirring and adjusted the $\mathrm{pH}$ to a certain value. The residual precipitate was collected by removing the water from the upper layer. The magnetic iron-iodine particles were washed down to a constant $\mathrm{pH}$ by bi-distilled water. The precipitate surface was stabilized by adding $40 \mathrm{mg}$ of citric acid/mg of precipitate for 2 hours at $80^{\circ} \mathrm{C}$ to get the compounds prepared in nano-scale. Several factors were studied, such as the iron-to-iodide molar ratio (2-0.334) at $\mathrm{pH} 12$ and $50^{\circ} \mathrm{C}, \mathrm{pH}(9-12.5)$ at $0.5 \mathrm{Fe} / \mathrm{I}$ molar ratio and $50^{\circ} \mathrm{C}$, reaction temperature $\left(25-80^{\circ} \mathrm{C}\right)$ at $0.5 \mathrm{Fe} / \mathrm{I}$ molar ratio and $\mathrm{pH} 12$.

Two samples (MII-1 and MII-2) were selected based on the iron and iodine ratios of the produced precipitate. MII-1 and MII-2 were prepared at a molar ratio of $0.5 \mathrm{Fe} / \mathrm{I}, 50^{\circ} \mathrm{C}$ at $\mathrm{pH} 12$ and $\mathrm{pH} 10$ respectively. The crystal size of the MIIs was stabilized by adding $40 \mathrm{mg}$ of citric acid/mg of MII to prepare MIINPs, at $80^{\circ} \mathrm{C}$ for 2 hours. The colloid solution was obtained by cooling to room temperature.

\section{Structural analysis of optimized MIINPs}

Several techniques were used to investigate the selected MIINPs compounds. Scanning Electron Microscope (SEM-JSM, 5600-LV), equipped with the Energy Dispersive X-ray (EDX-Oxford), Si-Li crystal $10 \times 3 \mathrm{~mm}$ in size ; thin windows $5 \mu \mathrm{m}$ beryllium; energy range $0-20 \mathrm{keV}$; resolution $137 \mathrm{keV}$ used to estimate the proportions of the elements $(\mathrm{O}, \mathrm{K}, \mathrm{S}, \mathrm{Fe}$ and $\mathrm{I})$ in the prepared compounds. To determine the proportions of hydrogen and nitrogen, elemental analysis was used. The JSX-3222 (XRF) analyzer, Japan (JEOL type) is an energy-dispersive $\mathrm{X}$-Ray fluorescence spectrometer (XRF). X-ray diffractometer (XRD) (X-lab Shimadzu X-6000) used a wavelength of $1.54^{\circ} \mathrm{A}$ diffractometer $\mathrm{Cu}-\mathrm{K \alpha}$ source for quantitative and qualitative analysis. MIINPs FTIR spectra in the 400 $4000 \mathrm{~cm}^{-1}$ range were used to determine the functional group in the prepared compounds. Fig. 1 displays a schematic diagram of the chemical structure assessment in preparation solution speciation, which was modeled using Visual Minteq 3.0 software to obtain the accessible cation and anion species during the reaction process. Assignments for the overall function group were discussed and preliminary crystalline phase identification was carried out using the Match 
1.9 software. Simulation of crystallographic structure was computitionally carried out using Endeavour 1.7, the initial crystallographic system, space group, cell parameters and molar content were set based on the EDX data. The simulation goodness was judged by calculating Mean Absolute Error (MAE) and Residual Square Mean Errors (RSME), as follows [50]:

$$
\begin{aligned}
& \text { MAE }=\frac{1}{n} \sum_{\mathrm{i}=1}^{\mathrm{n}}\left(\frac{\left|\mathrm{y}_{\mathrm{e}}-\mathrm{y}_{\mathrm{p}}\right|}{\mathrm{y}_{\mathrm{e}}}\right) \times 100 \\
& \mathrm{RSME}=\sqrt{\frac{1}{n} \sum_{\mathrm{i}=1}^{\mathrm{n}}\left(\mathrm{y}_{\mathrm{e}}-\mathrm{y}_{\mathrm{p}}\right)^{2}}
\end{aligned}
$$

Diamond 3.2 visualized the simulated structure and precisely groups function recognition was performed by assigning the deconvoluted FTIR spectra, where the simulated structure was used to guide deconvoluted peak assignment. A high-resolution electron transmission microscope (HR-TEM, Tecnai G20, FEI, Netherlands) was used to determine crystal size and structural morphology of MIINPs.

\section{Thermal and magnetic performances of the optimized samples}

Thermogravimetric (TG) and differential thermal analysis (DTA) were used to track changes in the mass of the selected MIINPs by raising the temperature to evaluate their thermal stability. The magnetic properties of the materials were measured using vibrating sample magnetometer (VSM) by Lake Shore Model 7410 from USA. The magnetic diameter $\left(\mathrm{D}_{\mathrm{m}}\right)$ distributions for the optimized samples were determined by fitting the magnetization curve to Langevin function L (a) using Log-Normal Distribution [51]:
$M(\alpha)=M_{S} \int_{0}^{\infty}\left(\frac{1}{\sqrt{2 \pi} D_{m} \ln (\sigma)} e^{\left(-\frac{\ln ^{2}\left(D_{m} / D_{m} v\right)}{2 \ln ^{2}(\sigma)}\right)}\right)\left((\alpha)-\frac{1}{\alpha}\right) d D_{m}$

$$
\alpha=\frac{\pi \mu \circ M_{d} D_{m}^{3} H}{6 k_{B} T}
$$

Where $M_{s}$ is is the measured saturation magnetization, $D_{m v}$ is the average magnetic diameter, $\ln (\sigma)$ is the standard deviation of the magnetic diameter distribution, $\mu_{o}$ is free space permeability, $M_{d}$ is the domain magnetization of the MIINPs, $k_{B}$ is the Boltzmann constant, and $\mathrm{T}$ is the absolute temperature.

The specific heat capacities of MIINPs were estimated by shaking $5 \mathrm{ml}$ aqueous solution (1 $\mathrm{mg}$ MIINPs/ml) in a glass tube and exposed them to the magnetic induction heater (DW-UHF-10 kW, China) with magnetic field strength $(\mathrm{H}=9.27 \mathrm{kA} / \mathrm{m})$ at a steady frequency $(\mathrm{f}=198 \mathrm{kHz})$. The specific absorption rate (SAR) was calculated using the following equation, depending on the Box - Lucas method [52]:

$$
\begin{aligned}
\Delta T & =a\left(1-e^{-b\left(t-t_{o}\right)}\right) \\
S A R & =\frac{a b C}{m_{M I I N P}}
\end{aligned}
$$

Where $\Delta \mathrm{T}$ and $\mathrm{t}$ are the temperature changes and time, $\mathrm{C}$ is the specific heat of aqueous solution, and $\mathrm{m}_{\text {MIINP }}$ is the magnetic particle concentration in the solution. The linear loss (L) and the intrinsic loss power (ILP) are determined by the following equation:

$$
\begin{aligned}
& L=b C \\
& I L P=\frac{S A R}{H^{2} f}
\end{aligned}
$$

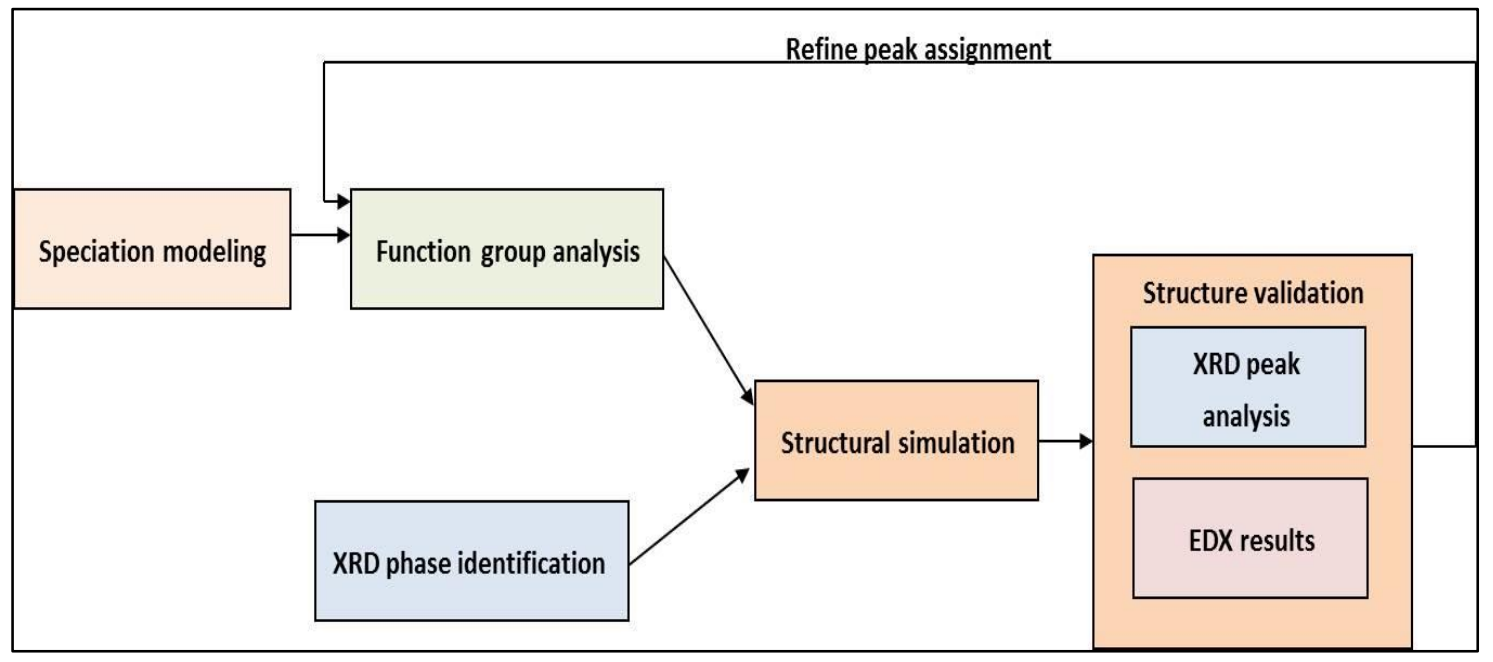

Fig. (1): MIINP characterization procedure 


\section{Cytotoxicity evaluation}

The cells were propagated in Dulbecco's modified Eagle's medium (DMEM) supplemented with $10 \%$ heatinactivated fetal bovine serum, $1 \%$ L-glutamine, HEPES buffer and $50 \mu \mathrm{g} / \mathrm{ml}$ gentamycin. All cells were maintained at $37^{\circ} \mathrm{C}$ in a humidified atmosphere with $5 \% \mathrm{CO}_{2}$ and were sub-cultivated two times a week. The cells were seeded in a 96-well plate at a cell concentration of $1 \times 10^{4}$ cells per well in a growth medium of $100 \mu \mathrm{l}$ for cytotoxicity assay. After $24 \mathrm{~h}$ of seeding, fresh medium containing different concentrations of samples of MIINPs was added. The microtiter plates were incubated for a 24-hour duration at $37^{\circ} \mathrm{C}$ in a humidified incubator with $5 \% \mathrm{CO}_{2}$. For each test sample concentration three wells were used. Control cells were incubated without test sample and with or without DMSO. It was found that the small amount of DMSO found in the wells (maximum $0.1 \%$ ) did not influence the experiment. The yield of viable cells was determined by a colorimetric method after incubation of the cells. Media were aspirated after the end of the incubation period and the crystal violet solution ( 1 percent) was added for at least 30 minutes to each well. The stain was removed, and tap water was used to rinse the plates until all excess stain was removed. Glacial acetic acid (30 percent) was added to all wells and mixed thoroughly, and then the absorbance of the plates is measured after gently shaken at $490 \mathrm{~nm}$ wavelength. All experiments were performed in triplicate. A calculation was made of the cell cytotoxic effect of each test compound. The optical density was measured to determine the number of viable cells, and this equation used to calculate the percentage of viability:

$$
\text { Viability yield }(\%)=\text { ODt } x 100 / O D c
$$

Where ODt is the mean optical density of wells treated with the tested sample and ODc is the mean optical density of untreated cell. The relation between surviving cells and drug concentration is plotted to get the survival curve of each cell line for the specified compound. The Cytotoxic concentration $\left(\mathrm{C}_{\mathrm{C} 50}\right)$, the concentration required to cause toxic effects in 50\% of intact cells, was estimated from graphic plots of the dose response curve for each concentration.

\section{RESULTS AND DISCUSSION}

\section{Optimal conditions for MIINPs preparation}

Fig. 2 (a, b, and c) studies the various parameters, such as temperature, $\mathrm{pH}$ and molar ratio, that affect the
MIINPs preparation method. The main objective of this work is to prepare MIINPs compounds similar to MNPs compounds, where an increase in the content of iodine in MIINPs does not affect their magnetic properties and their biological safety as MNPs compounds to be used for different purposes.

Fig. 2 (a) indicates that the iron ratio at room temperature is $12 \%$ higher than iodine, and the difference increased from 20 to $24 \%$, respectively, by increasing the temperature from 60 to $80^{\circ} \mathrm{C}$ with preserving the iron ratio superiority. The results could be attributed to the iodide $\left(\mathrm{I}^{-}\right)$is oxidized to volatile iodine $\left(\mathrm{I}_{2}\right)$ in the presence of $\mathrm{Fe}_{2} \mathrm{O}_{3}$ and $\mathrm{Fe}_{3} \mathrm{O}_{4}$ oxidizing species [37], which can lead to a reduction in the iodine ratio at $80^{\circ} \mathrm{C}$ around $25 \%$. The oxidizing species $\mathrm{Fe}_{2} \mathrm{O}_{3}$ and $\mathrm{Fe}_{3} \mathrm{O}_{4}$ were formed by the reaction of ferrous and ferric ions at $\mathrm{pH}>10$ [53]. The main factors affecting iodine evaporation are temperature and iodide concentration in the presence of oxidizing species $[37,54]$ according to the following reaction:

$$
2 \mathrm{Fe}_{(a q)}^{3+}+2 I_{(a q)}^{-} \stackrel{80^{\circ} \mathrm{C}}{\longrightarrow} 2 \mathrm{Fe}_{(s)}^{2+}+I_{2} \uparrow
$$

The possibility of preparing MIINPs compounds with a higher iodine content at $\mathrm{pH} 9$ was shown in Fig. 2 (b), a further increase in $\mathrm{pH}$, the iodine content would be decreased. The presence of iodide ion at $\mathrm{pH} 10$ may lead to the formation of $\gamma$-and $\alpha-\mathrm{Fe}_{2} \mathrm{O}_{2} \mathrm{I}$ as shown in equations (10-12), which is responsible for maintaining the iodine content superiority to iron.

$$
\begin{aligned}
& \mathrm{Fe}^{2+}+2 \mathrm{OH}^{-} \rightarrow \mathrm{Fe}(\mathrm{OH})_{2} \\
& \mathrm{Fe}^{3+}+2 \mathrm{OH}^{-}+\mathrm{I}^{-} \rightarrow \mathrm{FeOI}+\mathrm{H}_{2} \mathrm{O} \\
& \mathrm{FeOI}+\mathrm{Fe}(\mathrm{OH})_{2} \rightarrow \mathrm{Fe}_{2} \mathrm{O}_{2} \mathrm{I}+\mathrm{H}_{2} \mathrm{O}
\end{aligned}
$$

Increasing the $\mathrm{pH}>10$ lead to a decrease in the content of iodine in MIINPs compounds [53] as shown in equations (13-17).

$$
\begin{aligned}
& \mathrm{Fe}^{2+}+2 \mathrm{OH}^{-} \rightarrow \mathrm{Fe}(\mathrm{OH})_{2} \\
& 2 \mathrm{Fe}(\mathrm{OH})_{2} \rightarrow 2 \mathrm{FeO}+2 \mathrm{H}_{2} \mathrm{O} \\
& 2 \mathrm{FeO}+2 \mathrm{OH}^{-} \rightarrow 2 \mathrm{FeOOH} \\
& \mathrm{Fe}^{3+}+2 \mathrm{OH}^{-}+\mathrm{I}^{-} \rightarrow \mathrm{FeI}(\mathrm{OH})_{2} \\
& \mathrm{FeI}(\mathrm{OH})_{2}+2 \mathrm{FeOOH} \rightarrow \mathrm{Fe}_{3} \mathrm{O}_{4} \mathrm{I}+2 \mathrm{H}_{2} \mathrm{O}
\end{aligned}
$$




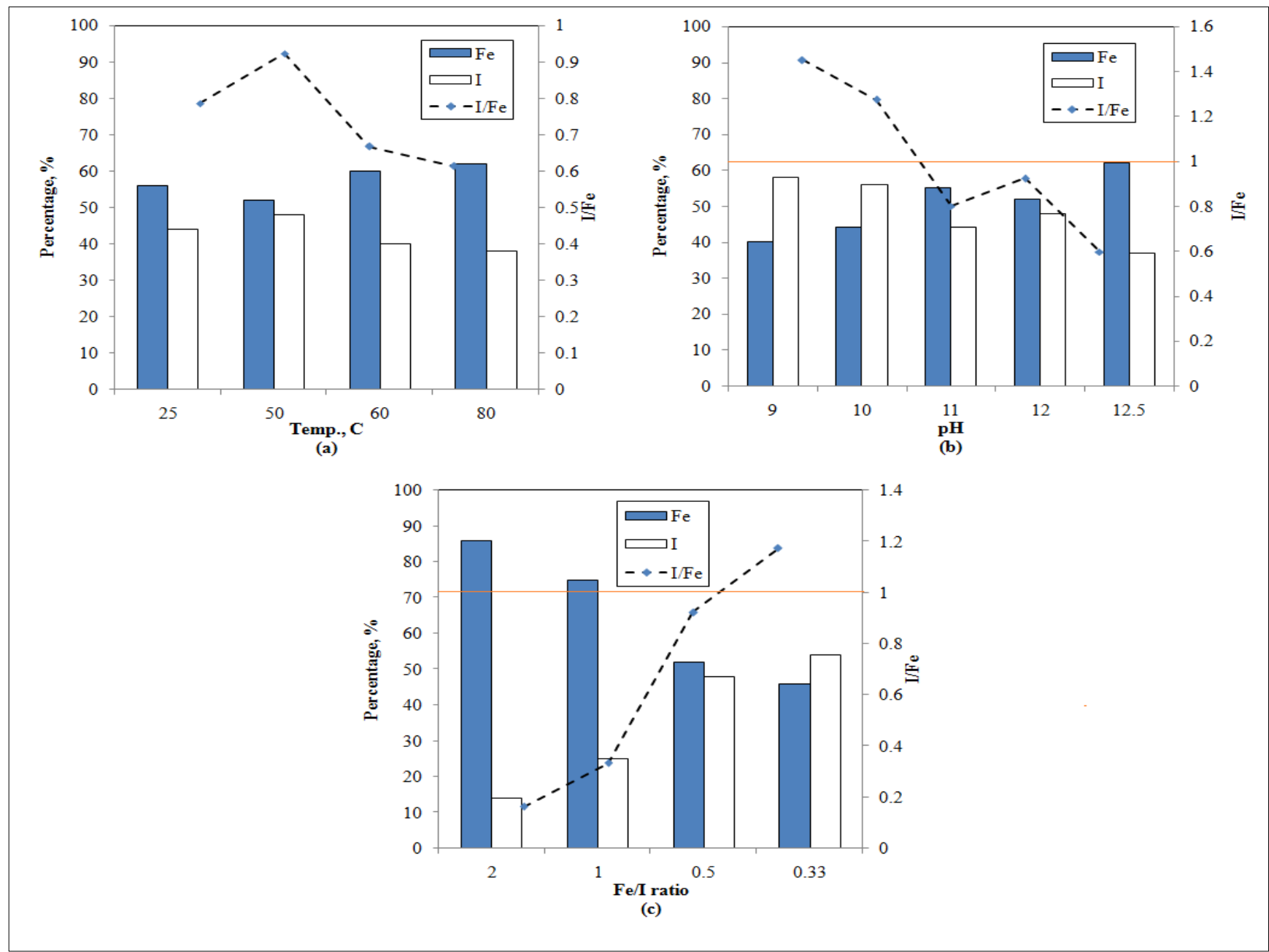

Fig. (2): MIINP optimization (a) Influence of temperature on MIINPs composition ( $\mathrm{Fe} / \mathrm{I}=0.5$ at $\mathrm{pH} 12)$, (b) Influence of $\mathrm{pH}\left(\mathrm{Fe} / \mathrm{I}=0.5\right.$, Temp. $\left.=50^{\circ} \mathrm{C}\right),(\mathrm{C})$ influence of $\mathrm{Fe} / \mathrm{I}$ ratio $\left(\mathrm{pH} \mathrm{12}, \mathrm{Temp} .=50^{\circ} \mathrm{C}\right)$

Table. (1): Comparison between the chemical compositions of the studied samples obtained as measured by EDX and calculated from the simulated structure.

\begin{tabular}{lcccccccc}
\hline Compound & Method & $\begin{array}{c}\text { Iron } \\
(\mathbf{\%})\end{array}$ & $\begin{array}{c}\text { Iodine } \\
\mathbf{( \% )}\end{array}$ & $\begin{array}{c}\text { Oxygen } \\
(\%)\end{array}$ & $\begin{array}{c}\text { Potassium } \\
\mathbf{( \% )}\end{array}$ & $\begin{array}{c}\text { Sulfur } \\
(\mathbf{\%})\end{array}$ & $\begin{array}{c}\text { Nitrogen } \\
(\%)\end{array}$ & $\begin{array}{c}\text { Hydrogen } \\
(\%)\end{array}$ \\
\hline MIINP-1 & Exp. & 39.5 & 13.0 & 21.3 & 10.5 & 10.7 & 5.0 & NA \\
& Calculated & 37.6 & 14.2 & 21.5 & 10.9 & 10.8 & 4.7 & 0.2 \\
MIINP-2 & Exp. & 18.1 & 61.8 & 5.8 & 5.5 & 4.2 & 4.5 & NA \\
& Calculated & 17.5 & 62.3 & 5.6 & 4.8 & 4.4 & 4.4 & 1.0 \\
\hline
\end{tabular}


Fig. 2(c) shows that decreasing the molar ratio of Fe/I from 2-0,334 during MIINP preparation results in a decrease of the iron ratio from $86-46 \%$ with an increase in the iodine ratio from $14-54 \%$. The results indicate that the maximum incorporation of iodine was obtained using Fe/I molar ratio of 0.33 .

Oxygen $\left(\mathrm{O}^{2-}\right)$ and iodide $\left(\mathrm{I}^{-}\right)$ions are competing to interact with ferrous $\left(\mathrm{Fe}^{2+}\right)$ and ferric $\left(\mathrm{Fe}^{3+}\right)$ ions in order to form stable MIINPs compounds. Pauling's crystal structure rule was applied in a cation-anion compound based on the proportion of the cation's ionic radius to the anion's ionic radius. This is simply given by $R_{C} / R_{A}$. The ionic radii of $\mathrm{Fe}^{2+}, \mathrm{Fe}^{3+}, \mathrm{O}^{2-}$, and I-are equal to 0.78 , $0.65,1.4$ and $2.2{ }^{\circ} \mathrm{A}$, respectively. The ratios of $\mathrm{R}_{\mathrm{Fe}^{2+}} / \mathrm{R}_{\mathrm{O}^{2-}}$, and $\mathrm{R}_{\mathrm{Fe}^{3+}} / \mathrm{R}_{\mathrm{O}^{2-}}$, are equal to 0.56 and 0.45 , respectively. The ratios of $\mathrm{R}_{\mathrm{Fe}^{2+}} / \mathrm{R}_{\mathrm{I}^{-}}$, and $\mathrm{R}_{\mathrm{Fe}^{3+}} / \mathrm{R}_{\mathrm{I}^{-}}$, are equal to 0.35 and 0.3 , respectively. The $\mathrm{Fe}^{+2}$ and $\mathrm{Fe}^{+3}$ ratios presented on the octahedral sites (0.41-0.73) with the oxygen ions and arranged on the tetrahedral sites $(0.23-0.41)$ with the iodide ions. The literature data confirmed $\mathrm{Fe}^{2+}$ ions present on the octahedral sites and $\mathrm{Fe}^{3+}$ ions are arranged on octahedral and tetrahedral sites [25]. Despite the sample with $\mathrm{Fe} / \mathrm{I}=0.33$ has the highest $\mathrm{I} / \mathrm{Fe}$ ratio of 1.2 , but this sample was not selected for further investigations as the excess KI precipitates were detected.

The two compounds are sample

(MIINP-1; $\mathrm{Fe} / \mathrm{I}=0.5$ at $\mathrm{pH} 12$ and $50^{\circ} \mathrm{C}$ ) and sample (b) (MIINP-2; Fe/I $=0.5$ at $\mathrm{pH} 10$ and $50^{\circ} \mathrm{C}$ ) were selected based on the percentages of iodide and iron as in sample (a), iodide (48\%) is lower than iron (52\%) and in sample (b) iodide (55\%) is higher than iron (45\%). The iodide in the MIINPs- 1 sample is bound to $\mathrm{Fe}^{3+}$ in the octahedral form, whereas the iodide in the MIINPs-2 sample is bound to $\mathrm{Fe}^{2+}$ and $\mathrm{Fe}^{3+}$ in the tetrahedral and octahedral forms.

\section{Characterization of the chosen MIINPs}

TEM images identified the size and morphology of MIINPs-1 and MIINPs-2. Fig. 3 (a, b) indicates that the crystal size of the two chosen samples exists in nanoscale. MIINPs- 1 crystalline sizes are smaller in the range of $5.85-7.25 \mathrm{~nm}$ and are more uniformly distributed than MIINPs-2, which ranges widely from 6.45-57.13nm.

Fig. S1 (a-d) shows the distribution of different species proportions in preparation solution of sample MIINPs-1 and MIINPs-2. The preparation conditions are clearly affected the forming species where oxides, hydroxides, ammonia, halides, and sulfates are the main expected groups.
The EDX spectra of MIINPs-1 and MIINPs-2 confirmed the presence of iron, iodine, oxygen, potassium and sulfur as shown in Fig. S2 $(\mathrm{a}, \mathrm{b})$. In addition to, Table 1 demonstrates the comparison between the chemical composition of the samples studied as determined practically by EDX and the calculated theoretically by simulation structure.

Fig. 4 and Table 2 illustrate the functional groups in the prepared samples. Preliminary investigations of MIINP-1 spectra showed a broad peak appears at 3173.6 $\mathrm{cm}^{-1}$ that may be due to the peaks overlap of the hydroxyl group and ammonium group. Two sharp and strong peaks were observed at 1092 and $614 \mathrm{~cm}^{-1}$ and correlated to sulfate group, and weak peaks at 886.7 and $892 \mathrm{~cm}^{-1}$ were attributed to $\mathrm{Fe}=\mathrm{O}$ and $\mathrm{Fe}=\mathrm{N}$, respectively [55]. Medium peaks appeared at 745 and $459.9 \mathrm{~cm}^{-1}$, which were attributed to Fe-I [56-59] and Fe-O [60]. For MIINP-2, two strong peaks at 3125 and $1396.2 \mathrm{~cm}^{-1}$ are shown and indicated the presence of the hydroxyl group. Two peaks at 1121.9 and $668.6 \mathrm{~cm}^{-1}$ were attributed to the sulfate group. Several peaks range 750-450, which are correlated to $\mathrm{Fe}-\mathrm{I}$ [56-59] and $\mathrm{Fe}-\mathrm{O}$ [60]. The peaks are more intense for MIINP-2 and shifted to a slightly lower wavelength that might indicate a stronger bond with iodide [61, 62]. FTIR spectra (Fig. 4), for both samples are consistent with the theoretical results (Fig. $\mathrm{S} 1(\mathrm{a}, \mathrm{b}))$ and confirms the presence of iron hydroxides species, ammonium sulfate and potassium sulfate in MIINPs- 1 and iron-iodine and oxides in the presence of hydroxides and sulfate salts in MIINPs-2 [61-72] It should be noted that nitrogen and oxygen bonding with hydrogen, either bending or stretching bands overlap in the ranges $1400-1600$ and $3000-3600 \mathrm{~cm}^{-1}$, respectively [61-65, 73-75] . So a detailed peak assignment could only be obtained after structure analysis.

The MIINPs-1 and MIINPs-2 crystalline structures were analyzed using XRD technique, as shown in Fig. 5. The XRD patterns of MIINPs- 1 and MIINPs-2 are very similar to the XRD analysis of $\alpha, \gamma-\mathrm{Fe}_{2} \mathrm{O}_{3}$ and $\mathrm{Fe}_{3} \mathrm{O}_{4}$ phases. These structures are difficult to distinguish due to both phases show high crystallinity. However, some literature data pointed to the XRD pattern associated with the maghemite phase as well as two additional peaks are at 23.77 (210) and 26.10 (211) respectively [50-52]. Maghemite phase is more prominent in the structure of MIINPs-1, and magnetite in MIINPs-2 structure. The presence of X-ray peaked at $21.5^{\circ}$ in both MIINPs is attributed to iodide [76]. On the other hand, the experimental data were compared with the preliminary analysis of XRD patterns in the supplementary file to check the reliability of the structure simulation in Figure (S.3 \& S.4). The simulated 
structure indicated that the final chemical formula is $\mathrm{Fe}_{48} \mathrm{I}_{8} \mathrm{O}_{96} \mathrm{~N}_{24} \mathrm{~S}_{24} \mathrm{~K}_{20} \mathrm{H}_{20}$, and $\mathrm{I}_{50} \mathrm{Fe}_{32} \mathrm{O}_{36} \mathrm{~K}_{12} \mathrm{~S}_{14} \mathrm{~N}_{32} \mathrm{H}_{104}$ for the MIINP-1 and MIINP-2, respectively. The proportions of elements were determined using the simulation results and compared to the EDX results as shown in Table 1 . The absolute errors in calculating of individual element \%in the range $\left(9 \times 10^{-4}-8 \times 10^{-2}\right)$ and $\left(8 \times 10^{-3}-1.22 \times 10^{-2}\right)$ for MIINP-1 and MIINP-2, respectively. The errors in calculating the chemical formula of MIINP-2 are greater than that of MIINP-1 this could be due to increased hydrogen inclusion in MIINP-2. The EDX results showed the content of Fe, K, $\mathrm{S}$ and $\mathrm{O}$ for the MIINP-2 sample, referring to limited inclusions of $\mathrm{FeSO}_{4}$ and $\mathrm{KSO}_{4}^{-}$in its MIINP-2 structure. Fig. 5 shows the bonds of the model structure for samples $(\mathrm{a}, \mathrm{b})$, the increased hydrogen content in the MIINP-2 is due to the presence of abundant ratio of water molecules. Examination of Figure S5 indicates that the iron coordination in both samples is affected by the incorporation of iodine. The coordination of iron is 4 in MIINP-1, and 6 in MIINP-2.
TGA curves of MIINPs-1 and MIINPs-2 in Fig. 6 (a, b) show three stages of decomposition behavior, the first is gradual in ranges $50-250^{\circ} \mathrm{C}$, followed by rapid decomposition in ranges $250-650^{\circ} \mathrm{C}$, and finally weight stability with further temperature increase. The first gradual losses are related to the loss of weakly bound water molecules, dehydration, and de-hydroxylation[77]. The peaks at 103 and $92^{\circ} \mathrm{C}$ with a weight loss of 1.39 and $4 \%$ for the MIINPs-1 and MIINPs-2, respectively, could be attributed to the removal of physical adsorbed hydroxyl on MIINPs as in MNPs [78]. The number of water molecules was calculated using the Alberti equation [79] for MIINPs-1 and MIINPs-2, and found to be 6 and 23 respectively. Broad diffraction peaks were observed at temperatures above $200^{\circ} \mathrm{C}$, and could be attributed to the formation of $\mathrm{Fe}_{2} \mathrm{O}_{3}$ and peak formation of goethite [28]. Mostly goethite $\left(\mathrm{HFeO}_{2}\right)$ and lepidocrocite $(\gamma-\mathrm{FeO}(\mathrm{OH}))$ were known in the 7 th edition of Dana's Mineralogy System as minerals of hydrous iron oxides [80] . Xi-Yun et al 2004 [81] pointed to the formation of $\mathrm{Fe}_{3} \mathrm{O}_{4}$ at the temperature $>200^{\circ} \mathrm{C}$.

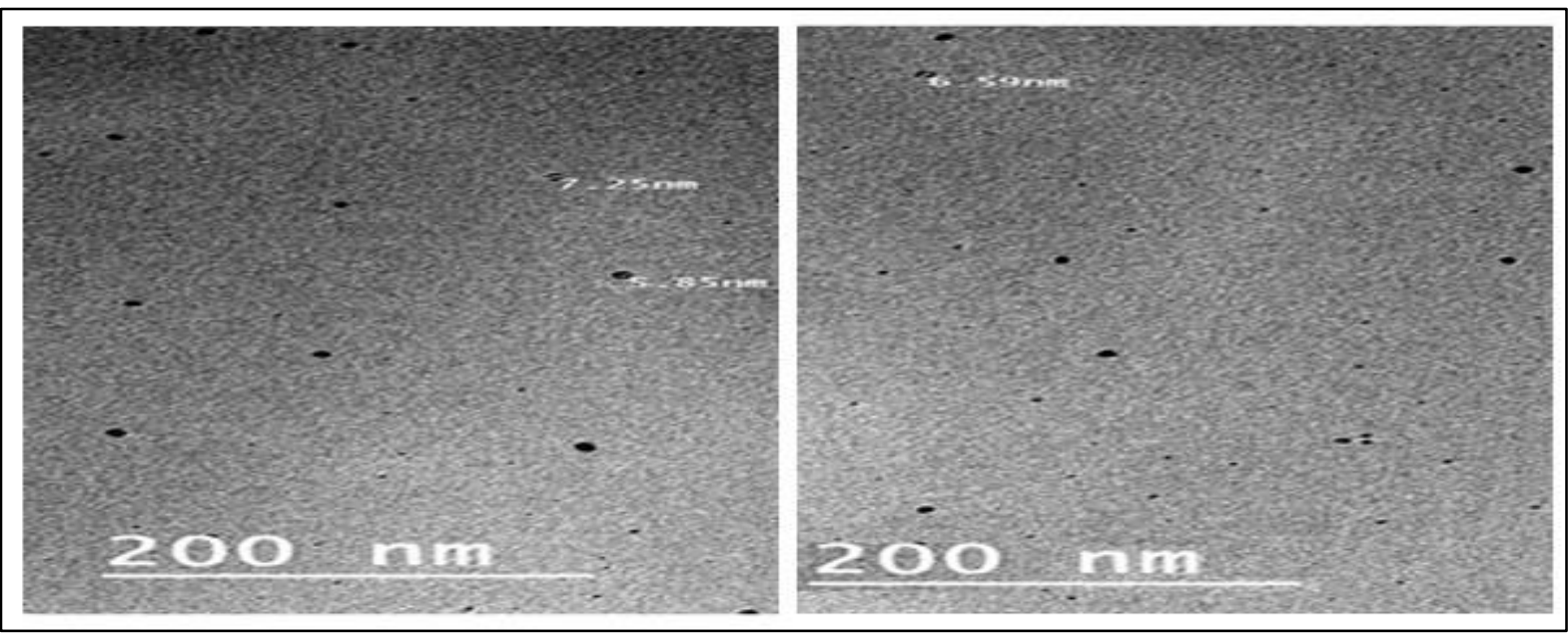

Fig. (3): TEM micrograph of (a) MIINPs-1 (b) MIINPs-2

Table (2): FTIR spectral analysis for sample (a) MIINPs-1 and (b) MIINPs-2

\begin{tabular}{|c|c|c|c|c|}
\hline Range & Sample (a) & Sample (b) & Peak assignment & Ref \\
\hline \multirow{3}{*}{$400-700$} & 412 & 400 & $\mathrm{Fe}^{2}-\mathrm{O}$ sym. bend octahedron position & \multirow{2}{*}{$60,64,74$} \\
\hline & 610 & 601 & $\mathrm{Fe}^{3}-\mathrm{O}$ tetrahedron position & \\
\hline & 782 & 786 & Saturate N-H third overtone stretching & 74 \\
\hline \multirow{2}{*}{$700-1400$} & - & 875 & M-Halide bending & 74 \\
\hline & 1101 & 1094 & S-O band & $51,62,64,74$ \\
\hline \multirow{4}{*}{$1400-3500$} & 1425 & 1403 & First N-H stretching with metal in coordination & 74 \\
\hline & 1610 & 1708 & $\begin{array}{l}\text { of O-H bending in water with increases I combination } \\
\text { with cation }\end{array}$ & $58,64,74$ \\
\hline & 2405 & $\begin{array}{l}2927 \\
2927\end{array}$ & $\mathrm{~N}-\mathrm{H}$ bending and strongly in $\mathrm{H} 2 \mathrm{O}$ & 64,65 \\
\hline & 3268. & 3209 & O-H stretching & $58,64,74$ \\
\hline
\end{tabular}



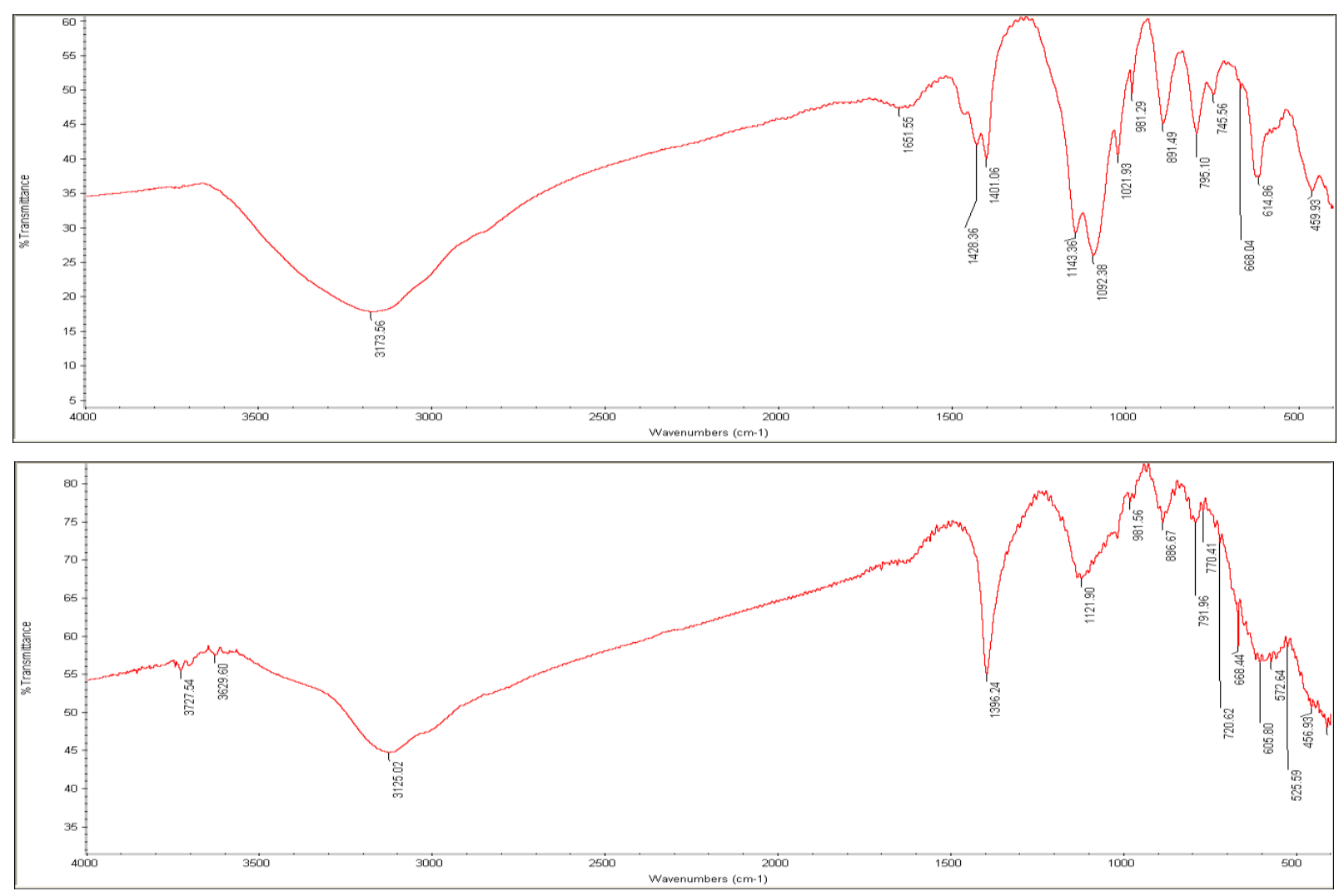

Fig. (4): FTIR spectra of the prepared magnetic iodide (a) MIINPs-1; (b) MIINPs-2
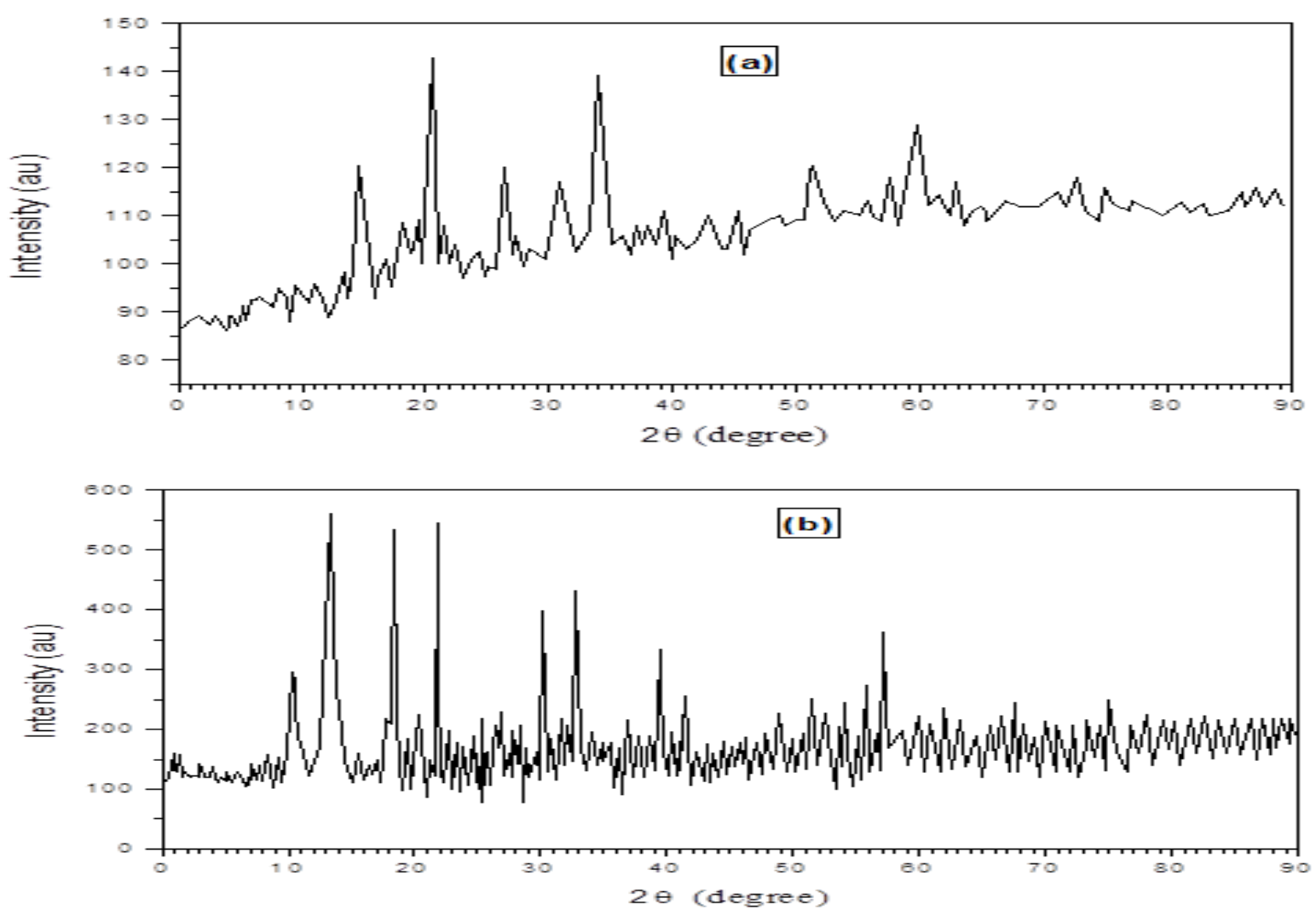

Fig. (5): XRD patterns and phase identification results for the iron iodide (a) MIINP-1 (b) MIINP-2 


\section{The feasibility of using MIINPs for several purposes}

TGA curves in Fig. 6 demonstrate that both MIINPs-1 and MIINPs-2 samples have thermal stability in the practical range for hyperthermia treatment of the cancer cells [4].

The magnetization curves show that both samples are superparamagnetic materials as shown in Fig. 7. Increasing the iodine content in MIINPs-2 led to a slight increase in the magnetism. The reported study indicated that an increase in the saturation magnetism is accompanied by increased coordination of iron in MNPs[82] .The magnetic parameters of the prepared materials were compared with the published data in literature, as shown in Table 3. It was found that the values of saturation magnetization at low coercive force (Hc) reach considerably high values [44, 82-83]. Both MIINPs-1 and MIINPs-2 samples have the same magnetization (nearly $36.1 \mathrm{emu} / \mathrm{g}$ ) in the $500 \mathrm{Oe}$ coercive field as safe operating limits for MHT, achieving $94 \%$ and $86.4 \%$ of their saturation values, respectively. Fig. S6 (a, b) shows the distribution of the magnetic diameters of the particle size that were evaluated by TEM for both samples. The particle size of MIINPs-1 $(5-7 \mathrm{~nm})$ is significantly smaller than the magnetic diameter $(15 \mathrm{~nm})$, which suggests strong magnetic dipole order on the surface layer (Fig. S6 (a))[52]. On the other hand, The MIINPs-1 particle size (about $7 \mathrm{~nm})$ is smaller than its magnetic diameter $(14.46 \mathrm{~nm})$, which suggests strong magnetic dipole order on the surface layer Fig. S 6 (a) [52]. On the other hand, the magnetic diameter of MIINPs-2 $(18 \mathrm{~nm})$ is smaller than of its particle size (about 57nm) in Figure S6 (b). Fig. S7 plotted the cumulative distribution function (CDF) of the magnetic diameter of 31 commercial MNPs, and the magnetic diameter of the MIINPs-1 and MIINPs-2 samples (14.46 and 18nm) that indicates the strong magnetic performance of the prepared samples.

The use of magnetic induction heater to raise the temperature of colloid solutions MIINPs-1 and MIINPs-2, indicating the temperature rise to $10{ }^{\circ} \mathrm{C}$ within 22 and 18 min, respectively as shown in Fig. S8. Fig. 8 shows that the experimentally measured SAR values for MIINPs-1 and MIINPs-2 are 59.6 and 79.9 Watt / g, and the calculated values are 58.72 and $61.26 \mathrm{Watt} / \mathrm{g}$ with coefficients of 0.988 and 0.968 , respectively. In case of MIINPs- 1 the calculated value was found to be similar to the measured value and was slightly different in the case of MIINPs-2. The linear losses of MIINPs-1 and MIINPs-2 were 28.18 and $29.9 \mathrm{Watt} / \mathrm{g}$ and intrinsic losses were were 3.45 and $3.6 * 10^{-3} \mathrm{nHm}^{2} / \mathrm{gm}$, respectively. To allow a clear comparison of the specific loss of these materials independently of the used magnetic field properties, ILP were calculated for the 33 commercial MNPs using Eq. (8). For the 33 commercial MNPS $_{\text {S }}$ SAR values were calculated and the cumulative distribution function of these materials was plotted as shown in Fig. S9. The results indicate that ILP of the prepared materials lies in the high 0.999 percentile, which indicates its excellent thermal properties.

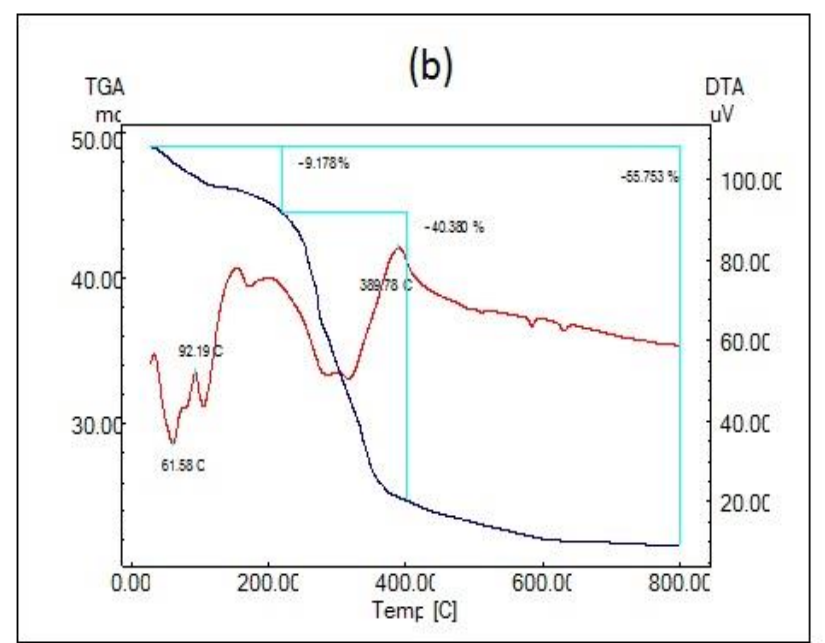

Fig. (6): TGA and DTA analysis of the prepared magnetic iron iodide (a) MIINPs-1; (b) MIINPs-2 


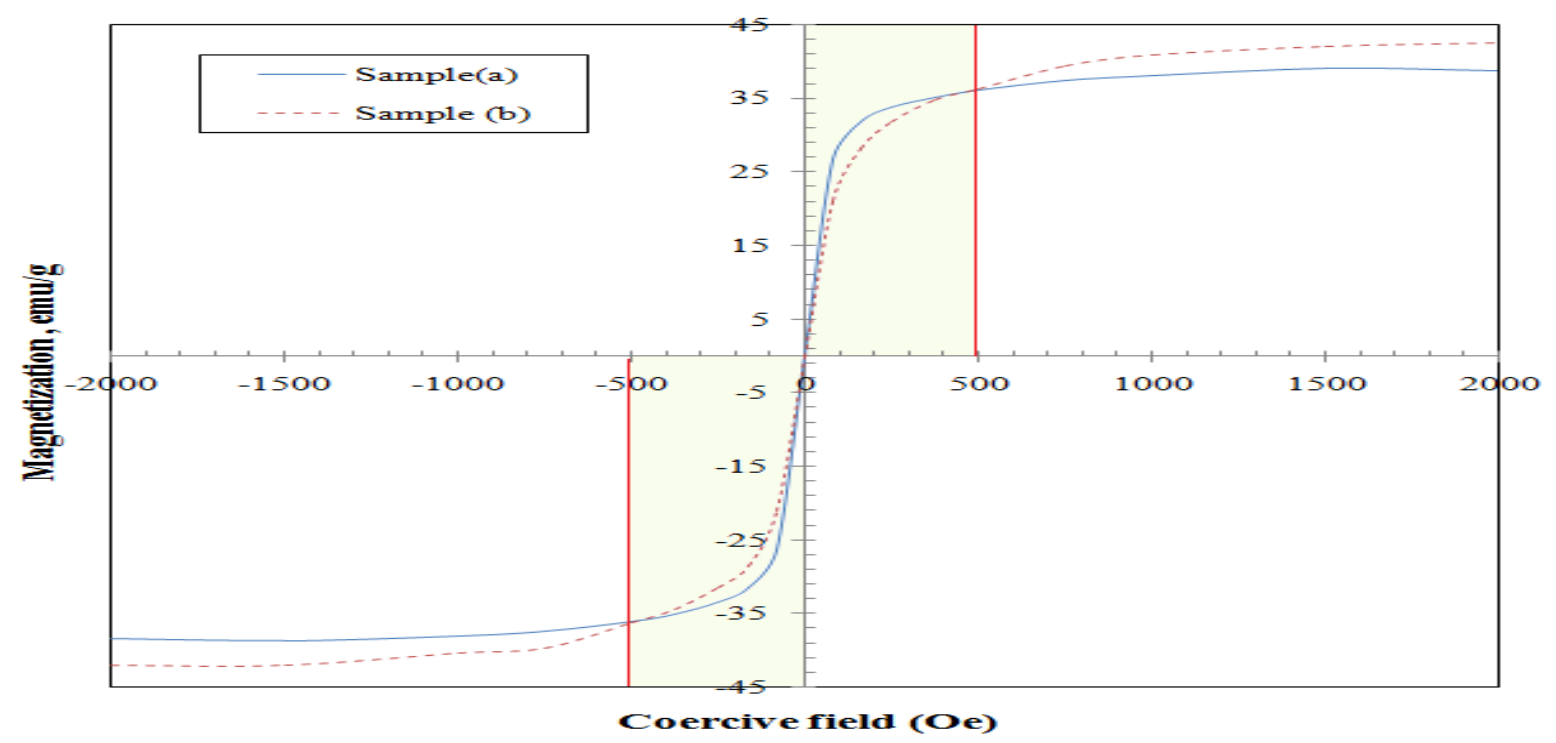

Fig. (7): Magnetization curves of MIINPs-1 and MIINPs-2

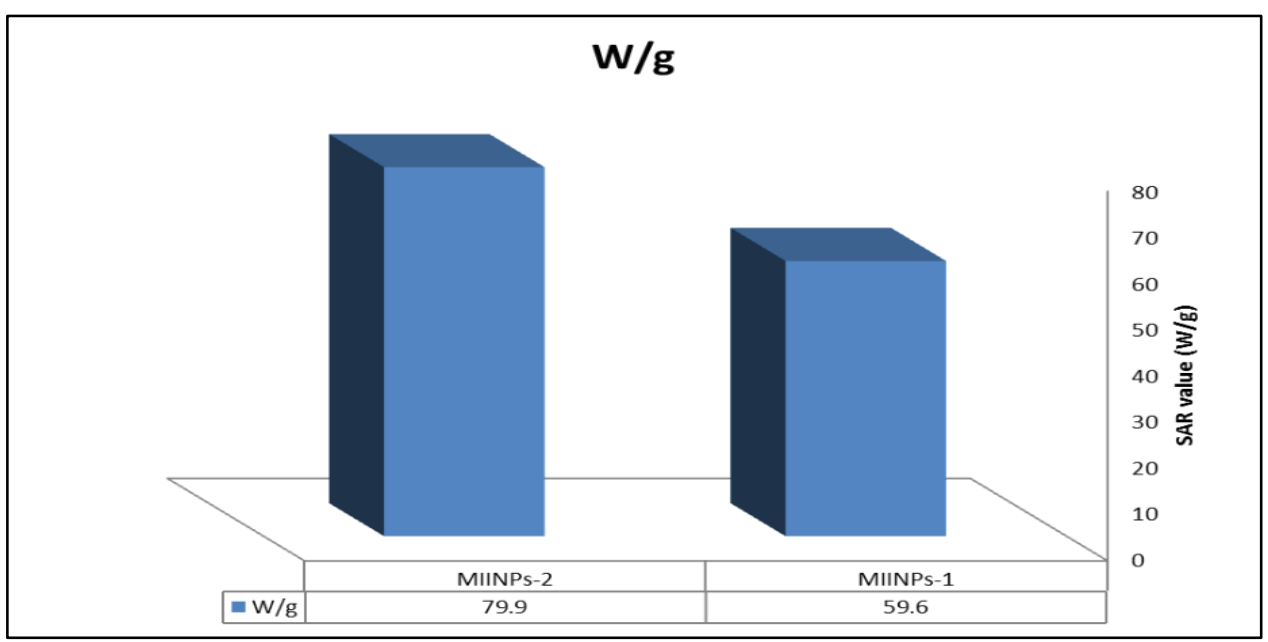

Fig. (8): Specific absorption rate (SAR) as a function of MIINPs compounds. at $v$ $198 \mathrm{kHz}$ and $H_{\text {max. }} \sim 9.27 \mathrm{kA} / \mathrm{m}$.

Table (3): comparison of the magnetic properties

\begin{tabular}{cccc}
\hline Sample & Ms (emu/g) & Hc (KOe) & Ref. \\
\hline MIINPs-1 & 38 & 1 & This work \\
MIINPs-2 & 42 & 1 & This work \\
Manganese ferrite & 43 & 1.563 & 82 \\
MNP & 20 & 2 & 44 \\
HA-MNP & 5 & 2 & 44 \\
MNP & 68 & 17.5 & 83 \\
Modified MNP & 60 & 17.5 & 83 \\
\hline
\end{tabular}

\section{Cytotoxicity}

Fig. 9 indicates a decrease of $20 \%$ in cell viability of the MIINPs-1 and MIINPs-2 concentrations of 75 and $200 \mu \mathrm{g} / \mathrm{ml}$, respectively. The cell viability decreased directly based on MIINPs-1 concentration, which is more affected at $100 \mu \mathrm{g} / \mathrm{ml}$. The critical concentrations of MIINPs-1 and MIINPs-2, which killed $50 \%$ of the cells, were evaluated at 237 and $434 \mu \mathrm{g} / \mathrm{ml}$. The cytotoxicity of MNPs in human cell lines has been previously studied and their safety for medical uses has been confirmed [84]. The MIINPs-2 is less toxic than MIINPs-1, which may be attributed to the high content of iodine and water molecules in MIINPs-2. MIINPs toxicity levels are compatible with previous studies [44] and shows that both of these compounds are safe for medical applications. 


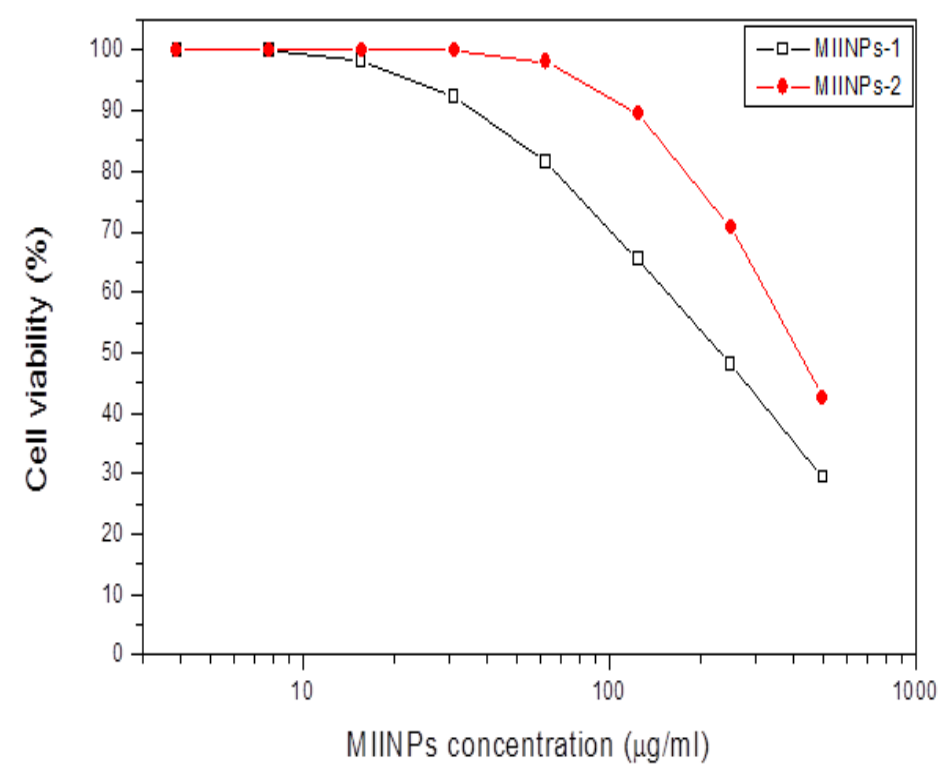

Fig. (9): Viability assays of the normal human lung fibroblast cells (MRC-5 cell) against the cytotoxicity of (a) MIINPs-1 and (b) MIINPs-2.

\section{CONCLUSION}

The co-precipitation method used to prepare new iron iodide magnetic nanoparticles compounds using variable molar ratios of iron to iodide, $\mathrm{pH}$ and reaction temperature. The iron-to-iodide molar ratios and the $\mathrm{pH}$ solution play an important role in preparing these compounds. The MIINPs- 2 and MIINPs- 1 could form effective magnetic species of $\mathrm{Fe}_{2} \mathrm{O}_{2} \mathrm{I}$ and $\mathrm{Fe}_{3} \mathrm{O}_{4} \mathrm{I}$, respectively. Due to a decrease in $\mathrm{pH}$ from 12 to 10 at a constant molar ratio of $\mathrm{Fe} / \mathrm{I}(0.5)$ and $50^{\circ} \mathrm{C}$, the iodine content in MIINPs-2 is greater than MIINPs-1. This can be attributed to the fact that the iron ions in the oxidation state $\mathrm{Fe}^{3+}$ are more than $\mathrm{Fe}^{2+}$ in MIINPs-1 at $\mathrm{pH}$ 12. On the other hand, with the high iron ratio in MIINPs-1, offset by a decrease in the iodide ratio, this resulted in a reduction of almost half of the toxicity of MIINPs-2 compared to MIINPs-1. Optimal nanoparticles are superparamagnetic materials (38 and $42 \mathrm{emu} / \mathrm{g}$ ), with specific absorption rates (SARs) of 59.6 and $79.9 \mathrm{~W} / \mathrm{g}$ for MIINPs-1 and MIINPs-2, respectively.

\section{Acknowledgements}

The authors thank Dr. Ismail Ali for measuring our samples on the magnetic induction device and the Egyptian cyclotron project staff for their gratitude.

\section{REFERENCES}

[1] Tseng C. L., Chang K. C., Yeh M. C., Yang K. C., Tang T. P., Lin F. H.(2014): Development of a dualfunctional Pt-Fe-HAP magnetic nanoparticles application for chemo-hyperthe-rmia treatment of cancer. Ceram Int. 40: 5117-5127.

[2] Heidari F., Razavi M., Bahrololoom M., Bazargan-Lari R., Vashaee D., Kotturi H., Tayebi L.(2016): Mechanical properties of natural chitosan/hydroxyapatite/magnetite

nanocomposites for tissue engineering applications. Mater. Sci. Eng. C Mater. Biol. Appl. 65: 338-344.

[3] Hu F., Wei L., Zhou Z., Ran Y., Li Z., Gao M.(2006): Preparation of biocompatible magnetite nanocrystals for in vivo magnetic resonance detection of cancer. Adv Mater. 18: 2553-2556.

[4] Song H., Choi J., Huh Y., Kim S., Jun Y., Suh J., Cheon J.(2005): Surface modulation of magneticnanocrystals in the development of highly efficient magnetic resonance probes for intracellularlabel ing. J. Am. Chem. Soc. 127: 9992-9993.

[5] Sudimack J. B. A., Lee R. J.(2000): Targeted drug delivery via the folate receptor. Adv. Drug Deliv. Rev. 41 : 147-162.

[6] Abdelhamid H. N., Talib A., Wu H. F.(2015): Facile synthesis of water soluble silver ferrite $\left(\mathrm{AgFeO}_{2}\right)$ nanoparticles and their biological application as antibacterial agents. RSC Adv. 44(5): 34594-34602.

[7] Wilczewska A. Z., Niemirowicz K., Markiewicz K. H., Car H.(2012): Nanoparticles as drug delivery systems. Pharmacol. Rep. 64 : 10201037

[8] Wang X., Zhuang J., Peng Q., Li Y. D.(2005) A general strategy for nanocrystals synthesis. Nature 437: $121-124$

[9] Nam J. M., Thaxton C. S., Mirkin C. A.(2003): Nanoparticle-based bio-bar codes for the ultrasensitive detection of proteins. Science 30 :1884-1886.

[10] Massart R.(1981):Preparation of aqueous magnetic liquids in alkaline and acidic media. IEEE Trans. Magn. 17: 1247-1248.

[11] Visalakshi G., Venkateswaran G., Kulshreshtha S. K., Moorthy P. N. (Com1993) : Positional characteristics of magnetite synthe-sized from aqueous solutions at temperatures up to $523 \mathrm{~K}$. Mater. Res. Bull. 28 : 829-836. 
[12] Kang Y. S., Risbud S., Rabolt J. F., Stroeve P.(1996): Synthesis and characterization of nanometer-size $\mathrm{Fe}_{3} \mathrm{O}_{4}$ and $\gamma-\mathrm{Fe}_{2} \mathrm{O}_{3}$ particles. Chem. Mater. 8 :2209-2211.

[13] Sahoo Y., Pizem H., Fried T., Golodnitsky D., Burstein L., Sukenik C. N., Markovich G.(2001): Alkyl phosphonate/phosphate coating on magnetite nanoparticles: a comparison with fatty acids. Langmuir 17: 7907-7911

[14] Tang J, Myers M, Bosnick K A, Brus L E 2003 Magnetite $\mathrm{Fe}_{3} \mathrm{O}_{4}$ nanocrystals: spectroscopic observation of aqueous oxidation kinetics. J. Phys. Chem. B 107 7501-7509

[15] Fried T., Shemer G., Markovich G.(2001) Ordered Two-dimensional arrays of ferrite nanoparticles. Adv. Mater. 13 : 1158-1161.

[16] Park J., An K., Hwang Y., Park J. G., Noh H. J., Kim J. Y., Park J. H., Hwang N. M., Hyeon T.(2004) Ultra-large-scale syntheses of monodisperse nanocrystals. Nat. Mater. 3: 891895.

[17] Yu M. K., Jeong Y. Y., Park J., Park S., Kim J. W., Min J. J., Kim K., Jon S.(2008): Drug-loaded superparamagnetic iron oxide nanoparticles for combined cancer imaging and therapy in vivo. Angew. Chem. Int. Ed. 47: 5362-5365.

[18] Beketov I. V., Safronov A. P., Medvedev A. I., Alonso J., Kurlyandskaya G. V., Bhagat S. M.(2012) Iron oxide nanoparticles fabricated by electric explosion of wire: Focus on magnetic nanofluids. AIP Adv. 2 : 022154-1-022154-24.

[19] Safronov A. P., Beketov I.V., Komogortsev S. V., Kurlyandskaya G. V., Medvedev A. I., Leiman D. V., Larrañaga A., Bhagat S. M.(2013) Spherical magnetic nanoparticles fabricated by laser target evaporation. AIP Adv. 3 : 052135-1052135-18

[20] Grossman J. H., Mc Neil S. E.(2012) Nanotechnology in Cancer Medicine. Phys. Today 65: 38-42.

[21] Martınez-Mera I., Espinosa-Pesqueira M. E., Perez-Hernandez R., Arenas-Alatorre J.(2007) Synthesis of magnetite (Fe3O4) nanoparticles without surfactants at room temperature. Mater. Lett. 61: 4447-4451.

[22] Wu J. H., Ko S. P., Liu H. L., Kim S., Ju J. S., Kim Y. K.(2007): Sub $5 \mathrm{~nm}$ magnetite nanoparticles: Synthesis, microstructure, and magnetic properties. Mater. Lett. 61: 3124-3129.

[23] Wu J. H., Ko S. P., Liu H. L., Jung M. H., Lee J. H., Ju J. S., Kim Y. K.(2008): Sub 5 nm Fe3O4 nanocrystals via coprecipitation method. Colloids Surf. Am. 313-314: 268-272.

[24] Valenzuela R., Fuentes M. C., Parra C., Baeza J., Duran N., Sharma S. K., Knobel M., Freer J.(2009): Influence of stirring velocity on the synthesis of magnetite nanoparticles (Fe3O4) by the co-precipitation method. J. Alloys Compd. 488: 227-231.

[25] Iwasaki T., Kosaka K., Watano S., Yanagida T., Kawai T.(2010a): Novel environmentally friendly synthesis of superparamagnetic magnetite nanoparticles using mechanochemical effect. Mater. Res. Bull. 45 : 481-485.

[26] Iwasaki T., Mizutani N., Watano S., Yanagida T., Kawai T.(2010b): Size control of magnetite nanoparticles by organic solvent-free chemical coprecipitation at room temperature. J. Exp. Nanosci. 5 : 251-262.

[27] Eken A. E., Ozenbas M.(2009):Characterization of nanostructured magnetite thin films produced by sol-gel processing. J. Sol-Gel Sci. Technol. 50: 321-327.

[28] Ozdemir O., Dunlop D.(2000):Intermediate magnetite formation during dehydration of Goethite. Earth and Planetary Science Letters 177: 59-67.

[29] Acharya S., Singh K.(2011):Microwave-assisted chemical reduction routes for direct synthesis of $\mathrm{Fe}-\mathrm{Pt}$ nanoparticles in ordered face-centered tetragonal L10 phase. Appl. Nanosci. 1: 97-101.

[30] Phani A. R., Passacantando M., Santucci S.(2007): Synthesis of nanocrystalline ZnTiO3 perovskite thin films by sol-gel process assisted by microwave irradiation.J .Phys. Chem. Solid 68: 317-323.

[31] Phani A. R., Santucci S.(2006): Evaluation of structural and mechanical properties of aluminum oxide thin films deposited by a sol-gel process: Comparison of microwave to conventi-onal anneal. J. Non-Crystall Solid 352:4093-4100.

[32] Hu L., Percheron A., Chaumont D., Brachais C. H.(2011): Microwave-assisted one-step hydrothermal synthesis of pure iron oxide 
nanoparticles: Magnetite, maghemite. J. Sol-Gel Sci. Technol. 60: 198-205.

[33] Tabis W., Lorenzo J. E., Kozlowski A., Tarnawski Z., Kakol Z., Mazzoli C., Walker H. C., Jaouen N., Mannix D., Marin C. (2013) :Effect of surface polishing and oxidization induced strain on electronic order at the Verwey transition in Fe3O4. Honig J. M. J. Phys. Condens. Matter. 25: 055603-005609.

[34] Huang D. J., Chang C. F., Chen J., Tjeng L. H., Rata A. D., Wu W. P., Chung S. C., Lina H. J., Hibma T., Chen C. T.(2002): Spin-resolved photoemission studies of epitaxial Fe3O4 (100) thin films. J. Magn. Magn. Mater. 239: 261-270.

[35] Liu X., Lu H., He M., Wang L., Shi H., Jin K., Wang C., Yang G.(2014): Room-temperature layer-by-layer epitaxial growth and characteristics of Fe3O4 ltrathin films. J. Phys. D. Appl. Phys. 47: 105004-105012.

[36] Ishigure K., Shiraishi H., Okuda H.(1988): Radiation chemistry of aqueous iodine systems under nuclear reactor accident conditions. Radiat. Phys. Chem. 32 : 593-601.

[37] Mutasim I. K.(2015): Co-precipitation in aqueous solution synthesis of magnetite nanoparticles using iron(III) salts as precursors. Arabian Journal of Chemistry $8: 279-284$.

[38] Dennis C. L., Jackson A. J., Borchers J. A., Ivkov R., Foreman A. R., Hoopes P. J., Strawbridge R., Pierce Z., Goerntiz E., Lau J. W., Gruettner C.(2008): The influence o magnetic and physiological behavior on the effectiveness of iron oxide nanoparticles for hyperthermia. J. Phys. D Appl. Phys.41 : 134020-134028.

[39] Kawai N., Futakuchi M., Yoshida T., Ito A., Sato S., Naiki T., Honda H., Shirai T., Kohri K.(2008): Effect of heat therapy using magnetic nanoparticles conjugated with cationic liposomes on prostate tumor in bone. Prostate 68: 784-792.

[40] Suto M., Hirota Y., Mamiya H., Fujita A., Kasuya R., Tohji K., Jeyadevan B.(2009): Heat dissipation mechanism of magnetite nanoparticles in magnetic fluid hyperthermia. J. Magn. Magn. Mater.321 : 1493-1496.

[41] Bae S., Lee S. W., Takemura Y., Yamashita E., Kunisaki J., Zurn S., Kim C. S.(2006): Dependence of frequency and magnetic field on self-heating characteristics of $\mathrm{NiFe} 2 \mathrm{O} 4$ nanoparticles for hyperthermia, IEEE Trans. Magn. 42: 3566-3568.

[42] Kaman O., Pollert E., Veverka P., Veverka M., Hadova E., Knýzek K., Marysko M., Kaspar P., Klementova M., Grunwaldova V., Vasseur S., Epherre R., Mornet S., Goglio G., Duguet E.(2009): Silica encapsulated manganese perovskite nanoparticles for magnetically induced hyperthermia without the risk of overheating. Nanotechnology 20: 275610-275617.

[43] Cheraghipour E., Javadpour S., Mehdizadeh A. R.(2012):Citrate capped superparamagnetic iron oxide nanoparticles used for hyperthermia therapy. J. Biomedical Science and Engineering 5: 715-719.

[44] Ahmadzadeh E., Talebnia F., Hosseini M.(2017):A biological method for in-situ synthesis of hydroxyapatite-coated magnetite nanoparticles using Enterobacter aerogenes: Characterization and acute toxicity assessments. Materials Science and Engineering C 73: 220224.

[45] Kim D. H., Lee S. H., Kim K. N., Kim K. M., Shim I. B., Lee Y. K.(2005):Cytotoxicity of ferrite particles by MTT and agar diffusion methods for hyperthermic application. Journal of Magnetism and Magnetic Materials 293(1) :287292.

[46] Kumar C. S. S. R., Mohammad F.(2011): Magnetic nanomat-erials for hyperthermia-based therapy and controlled drug delivery. Advanced Drug Delivery Reviews 63(9): 789-808.

[47] Goya G. F., Grazú V., Ibarra M. R.(2008): Magnetic nanoparticles for cancer therapy. Curr. Nanosci. $4: 1-16$.

[48] Perigo E. A., Hemery G., Sandre O., Ortega D., Garaio E., Plazaola F., Teran F. J.(2015):Fundamentals and advances in magnetic hyperthermia. Appl. Phys. Rev. 2(4) : 041302-1 041302-104.

[49] Blanco-Andujar C., Walter A., Cotin G., Bordeianu C., Mertz D., Felder-Flesch D., BeginColin S.(2016): Design of iron oxide-based nanoparticles for MRI and magnetic hyperthermia. Nanomedicine $11: 1889-1910$.

[50] Abdel Rahman R. O., Abdel Moamen O. A., Abdelmonem N., Ismail I. M.(2019): Optimizing the removal of strontium and cesium ions from binary solutions on magnetic nano-zeolite using 
response surface methodology (RSM) and artificial neural network (ANN). Environ. Res. 173: $397-410$.

[51] Unni M., Uh A. M., Savliwala S., Savitzky B. H., Dhavalikar R., Garraud N., Arnold D. P., Kourkoutis L. F., Andrew J. S., Rinaldi C.(2017): Thermal Decomposition Synthesis of Iron Oxide Nanoparticles with Diminished Magnetic Dead Layer by Controlled Addition of Oxygen. ACS Nano. 11: 2284-2303.

[52] Lanier O. L., Korotych O. I., Monsalve A. G., Wable D., Savliwala S., Grooms N. W. F., Tuitt C., Dobson J. (2019): Evaluation of magnetic nanoparticles for magnetic fluid hyperthermia. Int. J. Hyperthermia. 36(1):687701.

[53] Lian S., Wang E., Kang Z., Bai Y., Gao L., Jiang M., Hu C., Xu L.(2004):Synthesis of magnetite nanorods and porous hematite nanorods. Solid State Communications 129: 485-490.

[54] Lin C. C.(1980):Chemical effects of gamma radiation on iodine in aqueous solutions. J.Inorg. Nucl.Chem.42: 1101-1110.

[55] Majzlan J., Alpers C. N., Koch C. B., Mc Cleskey R. B., Myneni S. C. B., Neil J. M.(2011): Vibrational, X-ray absorption, and Mössbauer spectra of sulfate minerals from the weathered massive sulfide deposit at Iron Mountain, California. Chemical Geology 284: 296-305.

[56] Mutasim I. K.(2015): Co-precipitation in aqueous solution synthesis of magnetite nanoparticles using iron(III) salts as precursors. Arab. J. Chem. $8: 279-284$.

[57] Tartaj P., Morales M. P., Veintemillas-Verdaguer S., Gonzales-Carreno T., Serna J. C.(2003): The preparation of magnetic nanoparticles for applications in biomedicine. J. Phys. D Appl. Phys. 36 : R182-R197.

[58] Morales M. P., Pecharroman C., GonzalesCarreno T.(1994): Structural characteristics of uniform $\gamma$-Fe2O3 particles with different axial (length/width) ratios. J. Solid State Chem. 108: 158-163.

[59] Belin T., Guigue-Millot N., Caillot T., Aymes D., Niepce J. C.(2002): Influence of grain size, oxygen stoichiometry, and synthesis conditions on the $\gamma$-Fe2O3 vacancies ordering and lattice parameters. J. Solid State Chem. 163:459-465.
[60] Rowan A. D., Patterson C. H.(2009): Hybrid density functional theory applied to magnetite: Crystal structure, charge order, and phonons. Phys. Rev. B 79: 205103-1 - 205103-18.

[61] Stuart B.(2004): Infrared spectroscopy: fundamentals and applications. Wiley.

[62] Moumene T., Belarbi E., Haddad B., Villemin D., Abbas O., Khelifa B., Bresson S.(2015): Study of imidazolium dicationic ionic liquids by Raman and FTIR spectroscopies: The effect of the nature of the anion. J. Molecular Structure 1083: 179186.

[63] Chukanov N. V., Chervonnyi A. D.(2016):Infrared Spectroscopy of Minerals and Related Compounds. Springer Mineralogy, Springer International Publishing AG Switzerland.

[64] Nazari M., Ghasemi N., Maddah H., Motlagh M. M.(2014): Synthesis and characterization of maghemite nanopowders by chemical precipitation method, J Nanostruct Chem. 99(4): $1-5$.

[65] Gasser M. S., Mekhamer H. S., Abdel Rahman R.O.(2016): Optimization of the utilization of $\mathrm{Mg} / \mathrm{Fe}$ hydrotalcite like compounds in the removal of $\mathrm{Sr}(\mathrm{II})$ from aqueous solution. J. Env. Chem. Eng. 4: 4619-4630.

[66] Gasser M. S., El-Sherif E., Abdel Rahman R. O.(2017): Modification of $\mathrm{Mg}-\mathrm{Fe}$ hydrotalcite using Cyanex 272 for lanthanides Separation. J. Chem.Eng. 316 : 758-769.

[67] Miller F. A., Wilkins H.(1952):Infrared Spectra and characteristic frequencies of inorganic ions their use in qualitative analysis. Analytical Chemistry 24(8): 1253-1294.

[68] Lane M. D.(2007):Mid-infrared emission spectroscopy of sulfate and sulfate-bearing minerals. American Mineralogist. 92(1): 1-18.

[69] Branca C., D'Angelo G., Crupi C., Khouzami K., Rifici S., Ruello G., Wanderlingh U.(2016): Role of the $\mathrm{OH}$ and $\mathrm{NH}$ vibrational groups in polysaccharide nanocomposite interactions: A FTIR-ATR study on chitosan and chitosan/ clay films. Polymer 99: 614-622.

[70] Legodi M. A., Waal D. de.(2007):The preparation of magnetite, goethite, hematite and maghemite of pigment quality from mill scale iron waste. Dyes and Pigments. 74: 161-168. 
[71] Ruan H. D., Frost R. L., Kloprogge J. T.(2001): The behavior of hydroxyl units of synthetic goethite and its dehydroxylated product hematite. Spectrochimica Acta Part A.57: 2575-2586.

[72] Gonzlez M. A., Pavlovic I., Rojas-Delgado R., Barriga C.(2014): Removal of $\mathrm{Cu} 2+, \mathrm{Pb} 2+$ and $\mathrm{Cd} 2+$ by layered double hydroxide-humate hybrid. Sorbate and sorbent comparative studies, J. Chem. Eng. 254: 605-611.

[73] Peak D., Ford R. G., Sparks D. L.(1999): An in Situ ATR-FTIR Investigation of Sulfate Bonding Mechanisms on Goethite. J. Colloid Interface Sci. 218: 289-299.

[74] Villalobos M., Leckie J. O.(2001): Surface Complexation Modeling and FTIR Study of Carbonate Adsorption to Goethite. J. Colloid Interface Sci. 235: 15-32.

[75] Kumar D., Singh H., Jouen S., Hannoyer B., Banerjee S.(2015): Effect of precursor on the formation of different phases of iron oxide nanoparticles. RSC Adv. 5 : 7138-7150.

[76] Potassium iodide solubility (2019): http://periodic-table-of elements.org SOLUBILITY/potassium_iodide, last accessed (4 January, 2019).

[77] Ghaly M., Farida M. S. E. El-Dars, Hegazy M. M., Abdel Rahman R. O.(2016): Evaluation of synthetic Birnessite utilization as a sorbent for cobalt and strontium removal from aqueous solution.J.Chem. Eng. 284:1373-1385.
[78] Majeed J., Barick K. C., Shetake N. G., Pandey B. N., Hassan P. A., Tyagi A. K.(2015): Waterdispersible Polyphosphate Grafted $\mathrm{Fe} 3 \mathrm{O} 4$ Nanomagnets for Cancer Therapy. RSC.Adv. 5: 86754-86762.

[79] Alberti G., Torracca E.(1968): Crystalline insoluble acid salts of polyvalent metal and polybasic acid-6: preparation and ion exchange properties of crystalline titanium arsenate. J. Inorg. Nucl. Chem. 30:3075-3080.

[80] Frondel C.(1962): Dana's System of Mineralogy: Volume III: Silica Minerals. page 334.

[81] Xi-Yun Y., Zhu-qing G., Feng-liang L.(2004): Kinetics of $\mathrm{Fe} 3 \mathrm{O} 4$ formation by air oxidation $\mathrm{J}$. Cent South Univ. Technol. 11: 152 - 155.

[82] Vestal C. R., Zhang Z. J.(2003): Effects of Surface Coordination Chemistry on the Magnetic Properties of MnFe2O4 Spinel Ferrite Nanoparticles.J. Am. Chem. Soc. 125: 9828-9833.

[83] Chomchoey N., Bhongsuwan D., Bhongsuwan T.(2010): Magnetic Properties of Magnetite Nanoparticles Synthesized by Oxidative Alkaline Hydrolysis of Iron Powder. Kasetsart J. Nat. Sci. 44: 963-971.

[84] Watanabe M., Yoneda M., Morohashi A., Hori Y., Okamoto D., Sato A., Kurioka D., Nittami T., Hirokawa Y., Shiraishi T., Kawai K., Kasai H., Totsuka Y.(2013): Effects of Fe3O4 magnetic nanoparticles on A549 cells. Int. J. Mol. Sci. 14 : 15546-15560. 